\title{
Effects of applications of sewage sludge and fertilizer nitrogen on cadmium and lead contents of grass
}

\author{
O. J. Hemkes, A. Kemp and L. W. van Broekhoven \\ Centre for Agrobiological Research (CABO), Wageningen, Netherlands
}

Received 8 February 1983; accepted 3 June 1983

Key-words: sewage sludge, nitrogen fertilizer, cadmium, lead, soil, grass

\section{Summary}

During 5 successive years metal-bearing sewage sludge was applied on permanent grassland in amounts of $0,6,12$ and 18 tonnes per ha per year on a dry matter basis. Each sludge application was combined with various nitrogen treatments. The $\mathrm{Cd}$ content of the grass increased considerably with increasing amounts of sewage sludge and fertilizer-N. Moreover the content of $\mathrm{Cd}$ was higher in young than in old grass. The latter also applied to $\mathrm{Pb}$. However, the increase in the content of $\mathrm{Pb}$ was less and the relation between the supply of $\mathrm{Pb}$ and the $\mathrm{Pb}$ content of the grass was poor. During late autumn and winter the increase in $\mathrm{Pb}$ content was striking, which was probably caused by pollution from the atmosphere.

\section{Introduction}

In an earlier publication (Hemkes et al., 1980) the increase in production of sewage sludge and the use of a substantial part of this sludge in agriculture was pointed out. In that paper the effect of annual applications of sludge on the content of heavy metals in different layers of the soil profile was discussed. This paper only deals with the effect of annual applications of sewage sludge on the contents of $\mathrm{Cd}$ and $\mathrm{Pb}$ in the grass. Observations were also made on the metals $\mathrm{Zn}, \mathrm{Cu}, \mathrm{Ni}, \mathrm{Mo}, \mathrm{Mn}$ and $\mathrm{Fe}$, but these results are published elsewhere (Hemkes et al., 1983). The greater part of the data on the first year of the experiment is not considered here, since the uptake of the metals by the grass was very low because of slow movement of the metals into the soil and the low availability of the metals for the plants.

\section{Material and methods}

In 1973 a long-term field experiment was carried out on permanent grassland on a sandy soil (ca. $5 \%$ organic matter, $\mathrm{pH}(\mathrm{KCl}) 5.9$ in the $0-5 \mathrm{~cm}$ layer) at Wageningen. This experiment included four treatments with sewage sludge, indicated as S0, S6, S12 and S18 corresponding to $0,6,12$ and 18 tonnes of sludge per ha per year on 
a dry matter basis. Each year the sludge dressings were applied in February. To study the influence of nitrogen on the uptake of heavy metals by the grass, each sludge treatment was combined with four amounts of fertilizer-N, viz $0,30,60$ and $90 \mathrm{~kg}$ per ha per cut, indicated as N0, N30, N60 and N90 respectively. To get information on the accumulation of $\mathrm{Cd}$ and $\mathrm{Pb}$ in the grass at different stages of growth, the first cut of each treatment was mown at three different stages, viz 'grazing', 'silage grass' and 'hay grass'. The dry matter productions of these cuttings procedures amounted to about $1500-2000,3000-4000$ and $4000-5000 \mathrm{~kg}$ per ha, respectively. Throughout the growing season all treatments of the grazing stage were sampled to assess a possible effect of the season on the metal uptake. After the growing season sampling was continued up to January-February to study possible changes in metal contents in late autumn and winter.

To avoid damage to the sod by cutting too frequently, the experimental field was grazed by yearlings each other year. As a consequence, over the period of five years of sludge applications, only data of three years are available on the uptake of metals.

Methods of analysis were the same as described in the paper on the accumulation of heavy metals in the soil (Hemkes et al., 1980).

\section{Results and discussion}

Relationships between the amounts of $C d$ and $P b$ in the soil and the contents in grass The contents of $\mathrm{N}, \mathrm{Cd}$ and $\mathrm{Pb}$ of the sludge are shown in Table 1. The uptake of $\mathrm{Cd}$ and $\mathrm{Pb}$ by the grass was very low compared to the amounts supplied. The annual sludge dressings caused a sharp increase in the Cd content of the soil. Nevertheless, during the last year of the experiment the uptake of $\mathrm{Cd}$ by the grass was less than $1 \%$ of the amount supplied in that year. On the S18 treatment the Cd content in the $0-5 \mathrm{~cm}$ soil layer increased from 0.6 to $44 \mathrm{mg} / \mathrm{kg}$ during the 5 years of the experiment. This resulted in an increase in the Cd content of the grass from $0.2 \mathrm{mg} / \mathrm{kg}$ in 1973 to $2.4 \mathrm{mg} / \mathrm{kg}$ in the last year averaged over the growing season at a level of 420 $\mathrm{kg}$ of fertilizer-N per ha per year (Fig. 1). This figure shows that under our conditions a further increase in the amount of soil-Cd would not result in a plant-Cd content higher than $2.5-3 \mathrm{mg} / \mathrm{kg}$. In the meantime the $\mathrm{pH}(\mathrm{KCl})$ of the $0-5 \mathrm{~cm}$ layer of the same treatment increased from about 6 to about 7 . The results of pot trials (Williams \& David, 1976; Dijkshoorn et al., 1981) suggested that a decrease in this pH to a more normal level for sandy soil grasslands would lead to higher $\mathrm{Cd}$ contents in the grass. However, in this experiment it is difficult to predict to which value the $\mathrm{Cd}$

Table 1. Mean composition of the sewage sludge.

\begin{tabular}{lc}
\hline Dry matter $(\mathrm{g} / \mathrm{kg})$ & 265 \\
Organic matter $(\mathrm{g} / \mathrm{kg}$ & \\
$\mathrm{DM})$ & 456 \\
$\mathrm{~N}(\mathrm{~g} / \mathrm{kg} \mathrm{DM})$ & 22.4 \\
$\mathrm{Cd}(\mathrm{mg} / \mathrm{kg} \mathrm{DM})$ & 315 \\
$\mathrm{~Pb}(\mathrm{~g} / \mathrm{kg} \mathrm{DM})$ & 1130
\end{tabular}



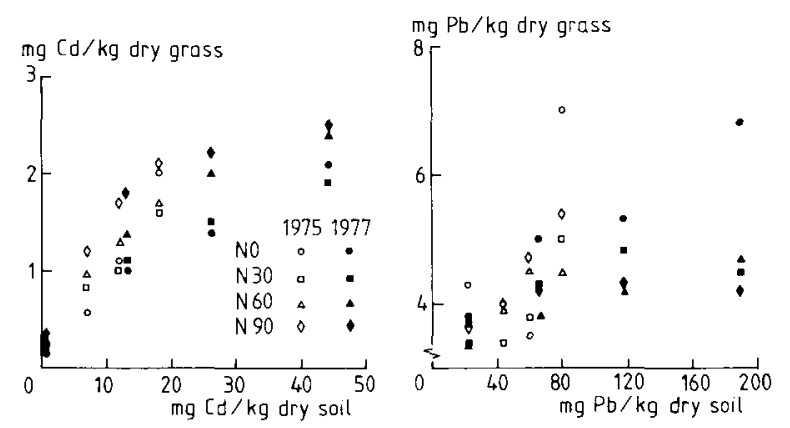

Fig. 1. The $\mathrm{Cd}$ and $\mathrm{Pb}$ contents in
grass (as a mean of the growing sea-
son) depending on the $\mathrm{Cd}$ and $\mathrm{Pb}$
contents in the $0-5 \mathrm{~cm}$ soil layer at
different amounts of fertilizer-nitro-
gen.

content might rise. A content of $10 \mathrm{mg} / \mathrm{kg}$ or even somewhat higher could be expected. A kind of ceiling in the Cd content of the grass was also mentioned by Williams \& David (1977). In pot trials with clover they found that an increase in the Cd content in the upper $2 \mathrm{~cm}$ of the soil up to $100 \mathrm{mg} / \mathrm{kg}$ did not raise the Cd content in the tops to more than about $44 \mathrm{mg} / \mathrm{kg}$. When this amount of soil $\mathrm{Cd}$ was mixed through the whole pot the Cd content of the crop increased to about $360 \mathrm{mg} / \mathrm{kg}$, going with a sharply depressed dry matter yield. This means that superficially applied sewage sludge on grassland can lead to much higher $\mathrm{Cd}$ contents in the grass after ploughing or milling and re-sowing.

An increase in the $\mathrm{Pb}$ content in the $0-5 \mathrm{~cm}$ soil layer from 20 to $80 \mathrm{mg} / \mathrm{kg}$ resulted in a slight increase in the $\mathrm{Pb}$ content of the grass (Fig. 1). Further increase in the content in the soil to almost $200 \mathrm{mg} / \mathrm{kg}$ did not result in a further increase in the $\mathrm{Pb}$ content of the grass. This agrees with the conclusions of Jones et al. (1973) and of Smilde (1981) that the $\mathrm{Pb}$ content of the crop is poorly correlated to soil- $\mathrm{Pb}$.

In Fig. 1 the contents in the grass are given separately for the different $\mathrm{N}$ levels. At a low Cd level of the soil nitrogen only affected the Cd content in the grass slightly. This effect of nitrogen was more distinct at higher $\mathrm{Cd}$ levels in the soil. Fig. 3 shows that in the separate cuts at high $\mathrm{N}$ levels the $\mathrm{Cd}$ content can be twice as high as at low $\mathrm{N}$ levels. The high $\mathrm{Cd}$ contents in the treatments without fertilizer- $\mathrm{N}$ were probably caused by soil pollution of the grass samples. There was no effect of fertilizer nitrogen on the content of lead in the grass.

\section{$C d$ and $P b$ contents of the grass in various stages of growth}

Since the $\mathbf{N}$ content of the grass decreased with the ageing of the grass the $\mathrm{N}$ content can be used as a standard of the growing stage. So it is possible to consider the metal content of the grass in relation to the content of nitrogen. This is done for the first cut of each growing stage, because the growing conditions were almost the same. Fig. 2 shows that without sludge application the relation was only weak between the nitrogen and cadmium contents in the grass. This relation was more distinct as the Cd supply was higher.

The difference in the $\mathrm{Pb}$ contents of the grass in different stages of growth were smaller than those in $\mathrm{Cd}$. Although the $\mathrm{Pb}$ content in young grass was higher, differences between 'silage grass' and 'hay grass' were only present in 1975. 

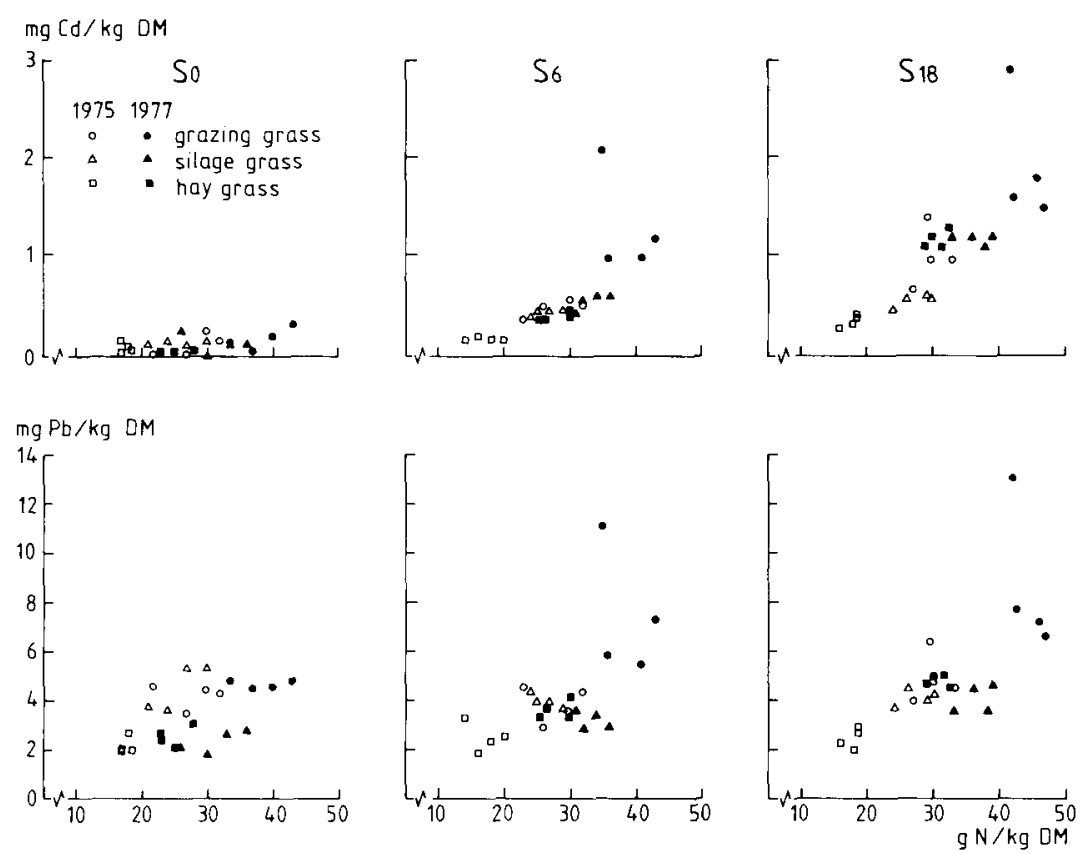

Fig. 2. Influence of the growth stage ( $\mathrm{N}$ content) on the contents of $\mathrm{Cd}$ and $\mathrm{Pb}$ in grass at different amounts of sewage sludge and fertilizer-nitrogen.

Seasonal variations in the $C d$ and $P b$ contents of the grass

The $\mathrm{Cd}$ content in pasture grass during the growing season and the following months after the different applications of sewage sludge and fertilizer-N is shown in Fig. 3. In the first months of the grazing period the $\mathrm{Cd}$ contents increased both with and without sludge applications. Later on the contents decreased again. The highest Cd content was $2.5 \mathrm{mg} / \mathrm{kg}$ as a mean of the growing season (Fig. 1). Particularly in the last year of the experiment, the $\mathrm{Cd}$ contents of the different cuts varied widely. Dependent on the $\mathrm{Cd}$ supply and the amount of fertilizer nitrogen applied values of over $4 \mathrm{mg} / \mathrm{kg}$ were found (Fig. 3). In winter the Cd contents were considerably lower than during the growing season.

Earlier it was stated that the $\mathrm{Pb}$ content of the grass hardly increased with increasing amounts of lead. This is also demonstrated in Fig. 4. In strong contrast with $\mathrm{Cd}$ there was an increase in the $\mathrm{Pb}$ contents up to $20-30 \mathrm{mg} / \mathrm{kg}$ during the months after the last cut. There was no relation between this increase and the supply of lead. Mitchell \& Reith (1966) also found a considerable increase in the Pb content of the grass after growth had stopped. According to their view, lead stored in the roots during the growing period, was probably transported to the aboveground portion after cessation of active growth. It may be expected, however, that the amount of accumulated lead in the roots will depend on the $\mathrm{Pb}$ content of the soil. Assuming that the amount of lead transported to the above-ground portion is 

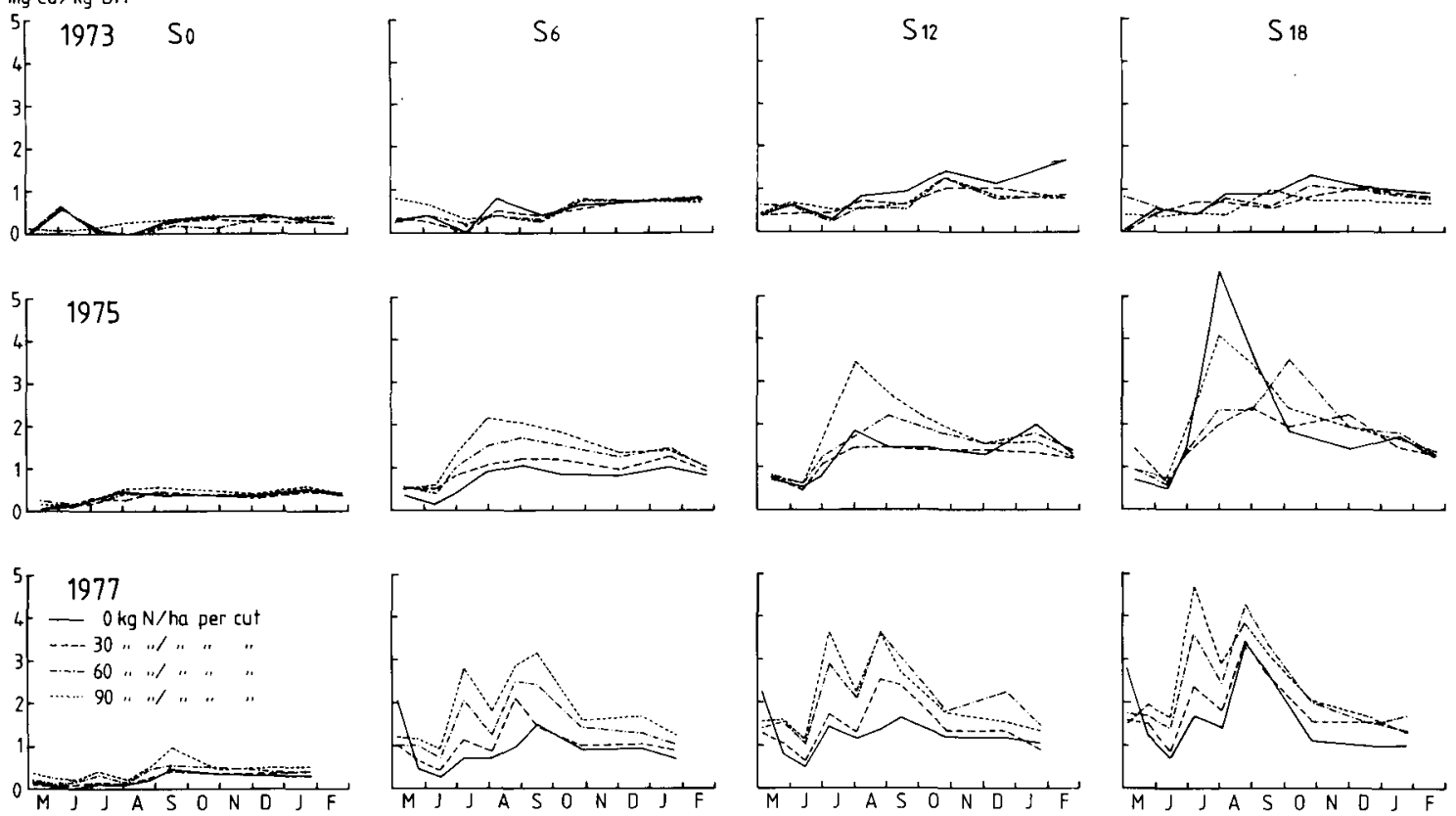

Fig. 3. The $\mathrm{Cd}$ content in grass during the growing season and of a few months after at different amounts of sewage sludge and fertilizer-nitrogen.
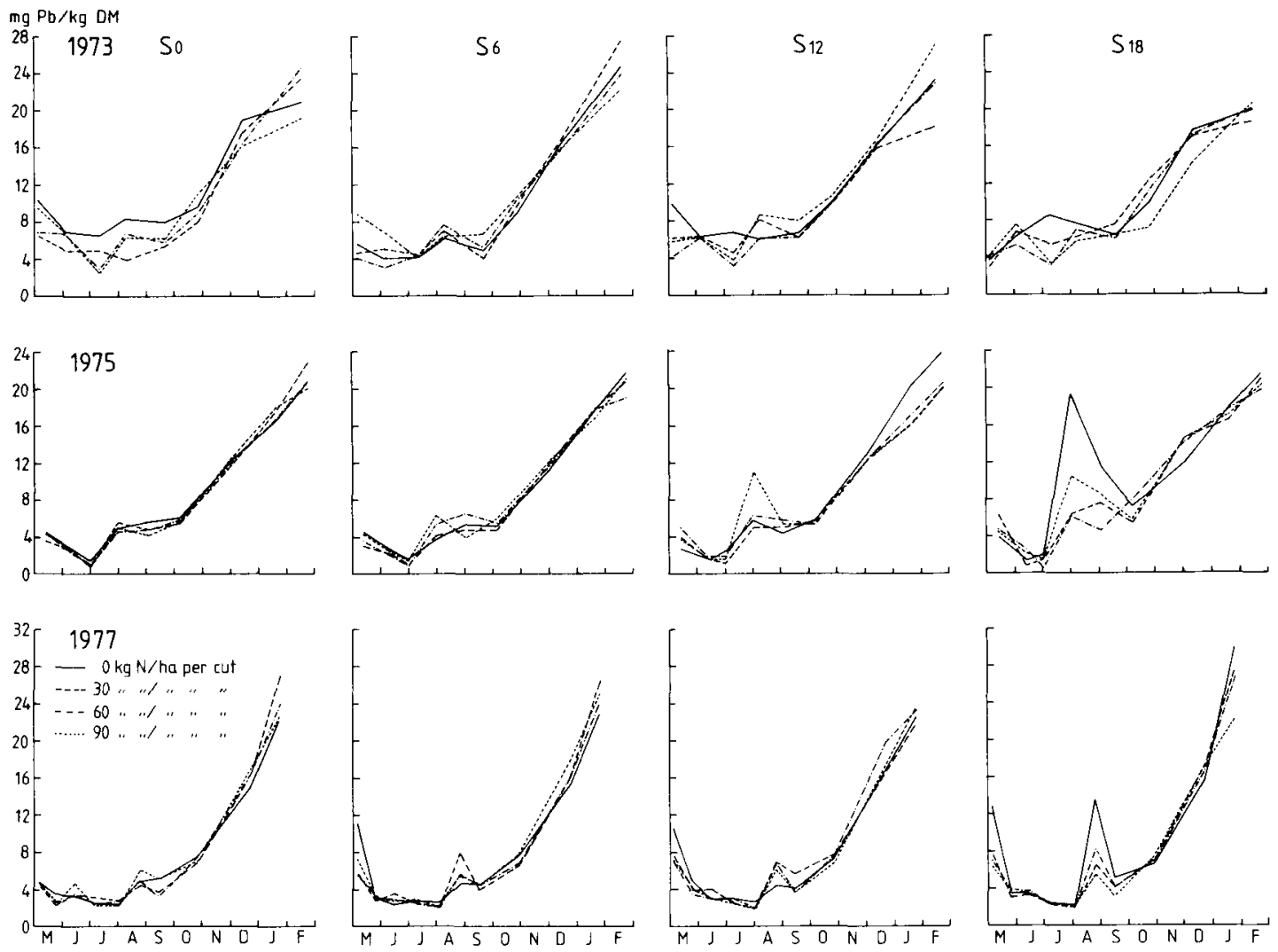

Fig. 4. The $\mathrm{Pb}$ content in grass during the growing season and of a few months after at different amounts of sewage sludge and fertilizer-nitrogen. 
related to the concentration of lead in the roots, as a consequence, there must be a relationship between the amount of transported lead and the $\mathrm{Pb}$ content of the soil. In the last year of our experiment there was a 10 -fold difference between the lowest and the highest $\mathrm{Pb}$ content of the soil. Nevertheless, in wintertime there was no difference in $\mathrm{Pb}$ contents of the grass of the different treatments. Therefore it is not likely that the increase in the $\mathrm{Pb}$ content during late autumn and winter was caused by transport of $\mathrm{Pb}$ from the roots to the tops or by soil pollution of the grass. Moreover, in the case of soil pollution the Cd contents should also have been increased. Fig. 3 shows, however, that the $\mathrm{Cd}$ contents decreased during this period. So the high $\mathrm{Pb}$ contents in grass during the winter may be explained by $\mathrm{Pb}$ pollution from the atmosphere. If the intensity of air pollution remains almost the same throughout the year, the much higher concentrations in wintertime can be explained by the very low dry matter production of the grass during this period of the year.

\section{References}

Dijkshoorn, W., J. E. M. Lampe \& L. W. van Broekhoven, 1981. Influence of soil pH on heavy metals in ryegrass from sludge-amended soil. Plant and Soil 61: 277-284.

Hemkes, O. J., A. Kemp \& L. W. van Broekhoven, 1980. Accumulation of heavy metals in the soil due to annual dressings with sewage sludge. Neth. J. agric. Sci. 28: 228-237.

Hemkes, O. J., A. Kemp \& L. W. van Broekhoven, 1983. Einfluss jährlicher Düngung von Gras mit Klärschlamm auf den Gehalt an Schwermetallen und auf den Trockensubstanzertrag. CABO-verslag No. 44.

Jones, L. H. P., S. C. Jarvis \& D. W. Cowling, 1973. Lead uptake from soils by perennial ryegrass and its relation to the supply of an essential element (Sulphur). Plant and Soil 38: 605-619.

Mitchell, R. L. \& J. W. S. Reith, 1966. The lead content of pasture herbage. J. Sci. Fd Agric. 17: 437440 .

Smilde, K. W., 1981. Heavy metal accumulation in crops grown on sewage sludge amended with metal salts. Plant and Soil 62: 3-14.

Williams, C. H. \& D. J. David, 1976. The accumulation in soil of cadmium residues from phosphate fertilizers and their effect on the cadmium content of plants. Soil Sci. 121: 86-93.

Williams, C. H. \& D. J. David, 1977. Some effects of the distribution of cadmium and phosphate in the root zone on the cadmium content of plants. Aust. J. Soil Res. 15: 59-68. 